\title{
Association Between Mode of Birth and Self-Reported Maternal Physical and Psychological Health Problems at 10 Weeks Postpartum
}

\author{
Jennifer Fenwick, Yvonne Hauck, Virginia Schmeid, Satvinder Dhaliwal, \\ and Janice Butt
}

\begin{abstract}
AIM: To determine the association between mode of birth and physical and psychological health problems reported at 10 weeks postpartum.

METHODS: A cross-sectional, self-report survey was completed by 2,699 Western Australian women at 10 weeks postpartum. Information on birth mode and physical and psychological health was sought. Descriptive statistics and frequency distributions were performed to describe the sample. Logistic regression was used to determine the association between mode of birth and the reported number of physical health problems (two or more and three or more) and two psychological health problems.
\end{abstract}

RESULTS: The occurrence of physical health problems for all women were incontinence (11.5\%), no bowel control (2.6\%), backache (41\%), heavy bleeding (14.1\%), and excessive fatigue or tiredness (35.7\%). A significant association was found between all cesarean sections (elective and emergency) and the number of physical health problems compared to spontaneous vaginal births. Women who had an emergency cesarean were most likely $(O R=3.15, \mathrm{CI}=2.40-4.13, p<0.0005)$ to report two or more physical problems, whereas women who had an elective cesarean were more likely $(O R=2.75, \mathrm{CI}=$ 2.08-3.63, $p<0.0005)$ to report three or more physical problems.

Nearly $15 \%$ of women reported being unhappy for more than a few days. This was highest in women having an emergency cesarean (16.4\%) and lowest in women giving birth spontaneously (13.5\%). Some $6.4 \%$ of women stated they were constantly reliving negative thoughts of birth and/or labor. Women who had an emergency cesarean were more likely $(O R=3.10, \mathrm{CI}=1.96-4.89, p<0.0005)$ to choose this item and they were also more likely $(O R=2.04, \mathrm{CI}=1.01-4.13, p<0.047)$ to experience both psychological health items.

CONCLUSION: Women's reports of health problems within the first 10 weeks postpartum are concerning and warrant ongoing attention. The prevalence of health problems was higher in women who had experienced a cesarean. This information on morbidity postbirth is essential for women and their care providers in making informed decisions around available birth options.

KEYWORDS: postpartum health; morbidity; mode of birth; emotional well-being; cesarean section

\section{INTRODUCTION}

Childbirth is a healthy process that is a significant and normal life event. Notwithstanding this normality, childbirth can be challenging as women adapt and negotiate its major physical, psychological, and social consequences. Postpartum morbidity and its impact on women's health after childbirth is an area of genuine concern (Bastos \& McCourt, 2010). Until recently, the assumption was often made that a woman's health will return to normal 
within 6 weeks of childbirth (Cheng \& Li, 2008). However, extensive work in the United Kingdom over the last two decades has demonstrated that some women experience long-term health problems as a result of childbirth (Bick, 2003; Williams, Herron-Marx, \& Knibb, 2007). MacArthur, Lewis, and Knox's (1991) groundbreaking work in the United Kingdom was the first real attempt to systematically document the extent of maternal morbidity during the first year after childbirth. In this study, the researchers found that $83 \%$ of women reported one or more physical health concerns during their first year postpartum. The researchers concluded that many of the childbirth-related health concerns remained hidden because "no one had thought to ask them (women) before" (MacArthur et al., 1991, p. 3). In Australia during the 1990s, similar results to those reported in the United Kingdom were identified by Brown and Lumley (1998). In their study of women 6 months postpartum, these researchers found that $94 \%$ of women reported problems; however, one third of these did not seek professional help. More recent work confirms these initial findings and has revealed that for some women, the common or "minor" problems associated with the postpartum period (such as backache, headache, fatigue, perineal pain, cesarean section [CS] wound discomfort, urinary and bowel problems, hemorrhoids, breast problems, and sexual dysfunction) when left untreated, may become chronic and debilitating, thus compromising physical, psychological, and social health (Bastos \& McCourt, 2010; Bick, 2003; MacArthur et al., 2003; Williams et al., 2007).

There is also concern over childbearing women's psychological well-being, as the mounting body of evidence suggests that mental health problems can have a major impact on the long-term well-being of women and their families (Commonwealth Department of Health and Aged Care \& Australian Institute of Health and Welfare [AIHW], 1999; Buist \& Blister, 2005; Buist et al., 2007; Lewis, 2004, 2007; National Health Medical and Research Council [NHMRC], 1999; Perinatal Mental Health Consortium, 2008). Although depression rates in postpartum women are thought to be between $10 \%$ and 15\% (Leigh \& Milgrom, 2008; Thompson, Roberts, \& Currie, 2002) whereas, Miller, Pallant, and Negri (2006) found that $29 \%$ of postpartum women had at least one classification of depression, anxiety, or stress. Similar figures have been consistently reported by Australian researchers Creedy, Shochet, and Horsfall (2000) and Gamble et al. (2005) who have identified that some $33 \%$ of postpartum women suffer symptoms associated with posttraumatic stress disorder (PTSD). These rates are concerning both in terms of women's long-term health and that of their children. A child's long-term emotional, behavioral, and cognitive development can be disturbed when their mother has suffered a postpartum mood disorder (Kendall \& Li, 2005; O'Conner, Heron, Golding, Beveridge, \& Glover, 2002; Sinclair \& Murray, 1998). Although some of the problems that new mothers may suffer during the postpartum period are more likely to be related to early parenting, others are more closely associated with the act of giving birth (Bastos \& McCourt, 2010). The context of the birth experience thus becomes important. In many resource-rich countries, the process of childbirth has become increasingly medicalized. The considerable and consistent rise in childbirth interventions (e.g., induction of labor, electronic fetal heart rate monitoring, use of epidurals, assisted and operative deliveries) over the last 30 years is a cause of concern (Althabe et al., 2006; Bastos \& McCourt, 2010; Williams et al., 2007). For example, in Australia, the CS rate is $31.8 \%$ (Laws, Li, \& Sullivan, 2010), with some states such as Western Australia reporting a rate as high as $33.2 \%$ (Le \& Tran, 2008). For those women giving birth within the private sector, the rate is more than $50 \%$ (Le \& Tran, 2008). This is despite the World Health Organization's (WHO, 1985) recommending rates of CS that should be between $10 \%$ and $15 \%$. Thus, the reality for many women in countries such as Australia is that they undertake the transition to motherhood while recovering from minor and/or major surgery. The implications of this on women's postpartum health remains poorly understood.

Although other states of Australia have investigated the health and well-being of postpartum women and provision of care (Bruinsma, Brown, \& Darcy, 2003; Cooke \& Stacey, 2003; Thompson et al., 2002), no such study had been undertaken within the state of Western Australia. The study aimed to address this gap by describing women's postpartum health needs and their perceptions of midwifery care in the early postpartum period. This article specifically reports on women's self-reported postpartum health and the association with mode of birth. Additional outcomes reported from the larger study include women's perceptions of the style and quality of midwifery's postpartum care in hospital and at home (Fenwick, Butt, Dhaliwal, Hauck, \& Schmied, 2010); breastfeeding initiation, prevalence, and early cessation patterns (Hauck, Fenwick, Dhaliwal, \& Butt, 2011); and perceptions of professional support and problems experienced on breastfeeding cessation (Hauck, Fenwick, Dhaliwal, Butt, \& Schmeid, 2011). These papers also provide supplementary details on the methodological approach used in this study. 


\section{METHODS}

\section{Study Design}

A cross-sectional survey was used to determine the association between mode of birth and physical and psychological health problems reported at 10 weeks postbirth. The postal questionnaire was distributed to every eligible Western Australian woman with a registered live birth between February and June 2006. Ethical approval was obtained from the university, and approval to access the database was obtained from the Western Australia Department of Health.

\section{Sample and Recruitment}

The Midwives Notification System (MNS) records and reports all births in Western Australia. Recruitment occurred via this database. Information packages (introductory letter, questionnaire, and reply-paid envelope) were posted by MNS managers to women 8 weeks postbirth. Women younger than 16 years of age and those mothers who experienced a perinatal death or whose baby required admission to the neonatal nursery for 7 days or more were excluded. Researchers did not have access to women's personal details. The questionnaires were not coded or linked to names and addresses; therefore, anonymity was assured.

\section{Sample Size and Power Calculation}

The sample size for this population-based survey was calculated on breastfeeding continuation rates at follow-up postbirth. Breastfeeding prevalence was used as the key outcome variable and to determine significant differences $(p<0.05)$ within $95 \%$ confidence interval (CI); the minimal sample size required was 2,449 (Hintz, 2008).

\section{Data Collection}

Over a 5-month period, 5,538 information packages were posted to Western Australian women and when 2,669 responded, recruitment ceased. The questionnaire used has been previously tested and used with Australian postpartum women and had a reported internal consistency (Cronbach's alpha) of 0.86 (Cooke, Sheehan, \& Schmied, 2003; Cooke \& Stacey, 2003).
Women provided general demographic and obstetric details. In relation to mode of birth, women selected from normal, instrumental, and elective or emergency CS. Information was sought on the content, quality, and style (way in which care is given) of postpartum care provided by midwives as well as any physical or mental health problem they may have experienced in the first 2 months after giving birth. This included vaginal stitches infected or breaking down, incontinence (loss of bladder control), no control of bowel motion, backache, abnormal heavy vaginal bleeding, excessive tiredness or fatigue, and pain from a cesarean wound. The questionnaire comprised two questions related to psychological health problems: "feeling down and unhappy for more than a few days" and "constantly reliving negative aspects of your labor or your baby's birth." Data were stored in accordance with the NHMRC recommendations.

\section{Data Analysis}

During the analysis for women experiencing a vaginal birth (normal or instrumental including forceps or vacuum), all items were considered except for "pain from a cesarean wound," whereas for women who experienced a cesarean birth (elective or emergency), the item "vaginal stitches infected or breaking down" was excluded. Descriptive statistics and frequency distributions were performed to describe the sample. Further analysis included cross tabulations and logistic regression analysis (Field, 2005). Logistic regression was used to determine the association between mode of birth and reported physical and the two psychological health problems. The effect of mode of birth for instrumental and elective and emergency cesarean births were compared to the reference of normal vaginal birth for the number of physical problems (two or more and three or more) and mental health problems after adjusting for hospital location, hospital type, and baby's age. Although the occurrence of each health problem is reported, the rationale for combining the number of problems is to capture a basic quantification for personal health burden by considering the number of health problems experienced by women. Personal health burden is rarely considered; in fact, burden of disease is more often considered and is measured by the cost to a population and/or society focusing on health services, workforce, and economics with no reference to individual experience (Begg et al., 2007). The effect of different modes of birth versus normal 
vaginal birth for the occurrence of maternal health problems is presented as adjusted odds ratios (OR) and associated 95\% CI. Data were analyzed using SPSS version 15 .

\section{RESULTS}

The 2,669 women responded to the questionnaire, which represents $9.45 \%$ of the Western Australia's birthing population in $2006(N=28,254)$. Although the questionnaire was posted at 8 weeks postbirth, $81 \%$ of women returned their completed questionnaire within 2 weeks, so 10 weeks is the reported outcome time period.

To determine whether our sample was representative, demographics were compared with the Western Australia perinatal statistics from 2006 (Gee, Ernstzen, \& Le, 2008) confirming there were similar characteristics for parity, type of birth, and maternal age older than 24 years (Table 1). However, single, teenage, aboriginal, and Torres Strait Islander mothers older than 24 years were underrepresented in our study. Most of our sample were multiparous (55.6\%), with just more than half (51.4\%) experiencing a normal vaginal birth. A high proportion of women (34.5\%) experienced a cesarean birth (elective and emergency), which is well above the recommended level of 15\% (WHO, 1985).

TABLE 1 Comparison of Study Sample to 2006 Western Australia Birthing Population

$\begin{array}{lccc} & \begin{array}{c}\text { 2006 STUDY } \\ \text { SAMPLE }\end{array} & \begin{array}{c}\text { 2006 WA PERINATAL } \\ \text { STATISTICS }\end{array} \\ & (\mathbf{N}=\mathbf{2 , 6 6 9 )} & \mathbf{( N = 2 8 , 2 5 4 )} \\ \text { Mother's age } & & & \\ 16-20 & 82(3.1 \%) & \leq 19 & (5.4 \%) \\ 21-25 & 325(12.2 \%) & 20-24 & (16.4 \%) \\ 26-30 & 796(29.8 \%) & 25-29 & (26.3 \%) \\ 31-35 & 991(37.1 \%) & 30-34 & (31.5 \%) \\ 36-40 & 417(15.6 \%) & 35-39 & (17.3 \%) \\ 41-45 & 13(2.2 \%) & 40-44 & (3.0 \%) \\ & & \geq 45 & (0.1 \%) \\ \text { Parity } & & & \\ \text { Primiparous women } & 1185(44.4 \%) & 41.8 \% & \\ \text { Multiparous women } & 1484(55.6 \%) & 58.2 \% & \\ \text { Type of Birth } & & & \\ \text { Normal vaginal birth } & 1368(51.4 \%) & 54.4 \% & \\ \text { Instrumental birth } & 377(14.2 \%) & 12.8 \% & \\ \text { Elective cesarean birth } & 602(22.6 \%) & 18.7 \% & \\ \text { Emergency cesarean } & 317(11.9 \%) & 14.0 \% & \\ \text { Breech maneuver } & \text { Missing } & 0.3 \% & \\ & & & \end{array}$

Note. WA $=$ Western Australia.

\section{Physical Health Problems}

Forty-one percent $(n=1,075)$ of women who responded experienced backache, and nearly 36\% $(n=913)$ stated they experienced excessive fatigue (refer to Table 2). Heavy vaginal bleeding was reported by $14.1 \%(n=369)$ of the women. Overall, $11.5 \%$ ( $n$ $=301$ ) of the women indicated that they had experienced urinary incontinence. This was highest for women who had an instrumental birth $(18.8 \%, n=69)$ compared to women who had a normal vaginal birth $(14.4 \%, n=194)$. In the group of woman who had an elective and emergency CS, the prevalence was 5.3\% $(n=31)$ and $2.2 \%(n=7)$, respectively. A further $2.6 \%$ $(n=68)$ reported that they had experienced any loss of bowel control.

Sixty-nine percent $(n=896)$ of women having a vaginal birth reported experiencing zero or one physical health problem compared to $43.6 \%(n=130)$ of women with an emergency CS and $51.1 \%(n=291)$ with an elective CS (Table 3 ). Of the women experiencing two or more problems, $56.4 \%(n=168)$ had an emergency CS, $48.9 \%(n=279)$ had an elective CS, and 30.9\% ( $n=401)$ had a normal vaginal birth. Prevalence of three of more physical problems is presented in Table 4.

Logistic regression analysis revealed a significant association between number of physical health problems reported and mode of birth (Table 5). The analysis adjusted for mother's parity, hospital location as a metropolitan or rural setting, and hospital type (private vs. public sector). Normal vaginal birth was used as the reference, and numbers of physical problems were analyzed in reference to zero or one problem compared to two or more problems and zero, one, or two problems compared to three or more. Women who had an instrumental birth (forceps or vacuum) were more likely to report experiencing two or more physical problems ( $O R$ $=1.40, \mathrm{CI}=1.08-1.83, p=0.012$ ) than those who had a normal vaginal birth. However, there was no significant difference between normal and instrumental births and women reporting three or more problems. A significant association was found between all cesarean births (elective and emergency) and the number of physical health problems (two or more and three or more) compared to spontaneous vaginal births. Women who had an emergency CS were most likely $(O R=3.15, \mathrm{CI}=$ $2.40-4.13, p<0.0005)$ to report two or more physical problems, whereas women who had an elective CS were more likely $(O R=2.75, \mathrm{CI}=2.08-3.63, p<0.0005)$ to report three or more physical problems. 
TABLE 2 Prevalence of Specific Physical and Mental Health Problems According to Mode of Birth at 10 Weeks After Birth

\begin{tabular}{|c|c|c|c|c|c|}
\hline $\begin{array}{l}\text { PHYSICAL HEALTH } \\
\text { PROBLEMS }\end{array}$ & $\begin{array}{c}\text { NORMAL } \\
\text { VAGINAL BIRTH } \\
n(\%)\end{array}$ & $\begin{array}{l}\text { INSTRUMENTAL } \\
\text { BIRTH } \\
n(\%)\end{array}$ & $\begin{array}{c}\text { ELECTIVE } \\
\text { CESAREAN BIRTH } \\
n(\%)\end{array}$ & $\begin{array}{c}\text { EMERGENCY } \\
\text { CESAREAN BIRTH } \\
n(\%)\end{array}$ & $\begin{array}{l}\text { TOTAL } \\
n(\%) \\
\quad N\end{array}$ \\
\hline $\begin{array}{l}\text { Incontinence (loss of } \\
\text { bladder control) }\end{array}$ & $194(14.4)$ & $69(18.8)$ & $31(5.3)$ & $7(2.2)$ & $\begin{array}{l}301(11.5) \\
N=2,617\end{array}$ \\
\hline $\begin{array}{l}\text { No control of bowel } \\
\text { motion }\end{array}$ & $34(2.5)$ & $14(3.8)$ & $13(2.2)$ & $7(2.2)$ & $\begin{array}{c}68(2.6) \\
N=2,617\end{array}$ \\
\hline Backache & $548(40.7)$ & $160(43.2)$ & $239(40.3)$ & $128(41.0)$ & $\begin{array}{l}1075(41.0) \\
N=2,622\end{array}$ \\
\hline Heavy vaginal bleeding & $196(14.6)$ & $49(13.2)$ & $83(14.0)$ & $41(13.1)$ & $\begin{array}{l}369(14.1) \\
N=2,620\end{array}$ \\
\hline $\begin{array}{l}\text { Excessive tiredness or } \\
\text { fatigue }\end{array}$ & $461(35.1)$ & $123(34.4)$ & $211(36.1)$ & $118(38.8)$ & $\begin{array}{l}913(35.7) \\
N=2,561\end{array}$ \\
\hline $\begin{array}{l}\text { Vaginal stitches infected } \\
\text { or breaking down } \\
\text { (vaginal birth only) }\end{array}$ & $106(7.8)$ & $51(13.7)$ & & & $\begin{array}{c}157(9.1) \\
N=1,726\end{array}$ \\
\hline $\begin{array}{l}\text { Pain from a cesarean } \\
\text { wound (cesarean birth } \\
\text { only) }\end{array}$ & & & $412(68.8)$ & $235(74.4)$ & $\begin{array}{l}647(70.7) \\
N=915\end{array}$ \\
\hline \multicolumn{6}{|l|}{$\begin{array}{l}\text { MENTAL HEALTH } \\
\text { PROBLEMS }\end{array}$} \\
\hline $\begin{array}{l}\text { Unhappy feeling for } \\
\text { more than a few days }\end{array}$ & $181(13.5)$ & $59(16.0)$ & $89(15.1)$ & $51(16.4)$ & $\begin{array}{l}380(14.6) \\
N=2610\end{array}$ \\
\hline $\begin{array}{l}\text { Reliving negative thoughts } \\
\text { of birth/labor }\end{array}$ & 65 (4.9) & $39(10.6)$ & $24(4.1)$ & $37(12.0)$ & $\begin{array}{l}165(6.4) \\
N=2,597\end{array}$ \\
\hline
\end{tabular}

\section{Psychological Health Concerns}

In relation to psychological health, $14.6 \%(n=380)$ of the women reported experienced feeling unhappy for more than a few days (Table 2). This was highest in women experiencing an emergency CS $(16.4 \%, n=51)$ and an instrumental birth $(16 \%, n=59)$ and lowest in women reporting a normal vaginal birth $(13.5 \%, n=181)$. For those women who had an elective CS, $15.1 \%$

TABLE 3 Prevalence of Physical Problems $(<2$ or $\geq 2)$ According to Mode of Birth

\begin{tabular}{|c|c|c|c|}
\hline \multirow[b]{2}{*}{ MODE OF BIRTH } & \multicolumn{3}{|c|}{ PHYSICAL PROBLEMS } \\
\hline & $\begin{array}{l}\text { 0 TO } 1 \\
n(\%)\end{array}$ & $\begin{array}{c}2 \text { OR MORE } \\
n(\%)\end{array}$ & $\begin{array}{l}\text { TOTAL } \\
n(\%)\end{array}$ \\
\hline $\begin{array}{l}\text { Normal vaginal } \\
\text { birth }\end{array}$ & $896(69.1)$ & 401 (30.9) & $\begin{array}{c}1297 \\
(100)\end{array}$ \\
\hline $\begin{array}{l}\text { Instrumental } \\
\text { birth }\end{array}$ & $223(63.5)$ & $128(36.5)$ & $\begin{array}{l}351 \\
(100)\end{array}$ \\
\hline Elective cesarean & $291(51.1)$ & $279(48.9)$ & $\begin{array}{l}570 \\
(100)\end{array}$ \\
\hline $\begin{array}{r}\text { Emergency } \\
\text { cesarean }\end{array}$ & $130(43.6)$ & $168(56.4)$ & $\begin{array}{l}298 \\
(100)\end{array}$ \\
\hline
\end{tabular}

( $n=89)$ indicated they also experienced unhappy feelings. The second psychological item focused on reports of "reliving negative thoughts of birth and labor." Prevalence of this item differed across the four birth mode groups. The highest percentage of $12 \%(n=37)$ was associated with those who had an emergency CS with the second highest $(10.6 \%, n=39)$ prevalence with those who had an instrumental birth. The percentage of women who had a spontaneous vaginal birth $(4.9 \%$,

TABLE 4 Prevalence of Physical Problems $(<3$ or $\geq 3)$ According to Mode of Birth

\begin{tabular}{|c|c|c|c|}
\hline \multirow[b]{2}{*}{ MODE OF BIRTH } & \multicolumn{3}{|c|}{ PHYSICAL PROBLEMS } \\
\hline & $\begin{array}{c}0 \text { TO } 2 \\
n(\%)\end{array}$ & $\begin{array}{c}3 \text { OR MORE } \\
n(\%)\end{array}$ & $\begin{array}{l}\text { TOTAL } \\
n(\%)\end{array}$ \\
\hline $\begin{array}{l}\text { Normal vaginal } \\
\text { birth }\end{array}$ & $1149(88.6)$ & $148(11.4)$ & $\begin{array}{l}1297 \\
(100)\end{array}$ \\
\hline $\begin{array}{l}\text { Instrumental } \\
\text { birth }\end{array}$ & 305 (86.9) & $46(13.1)$ & $\begin{array}{l}351 \\
(100)\end{array}$ \\
\hline Elective cesarean & $443(75.0)$ & $137(24.0)$ & $\begin{array}{l}570 \\
(100)\end{array}$ \\
\hline $\begin{array}{r}\text { Emergency } \\
\text { cesarean }\end{array}$ & $227(76.0)$ & $71(23.8)$ & $\begin{array}{l}298 \\
(100)\end{array}$ \\
\hline
\end{tabular}


TABLE 5 Association of Mode of Birth on Physical Problems Using Logistic Regression Analyses

\begin{tabular}{lcc} 
& \multicolumn{2}{c}{ PHYSICAL PROBLEMS } \\
$\begin{array}{lcc}\text { MODE OF BIRTH } & \text { 2 OR MORE VS. 0 OR 1 } & \text { 3 OR MORE VS. 0 OR 1 } \\
\text { OR 2 }\end{array}$ \\
$\begin{array}{l}\text { Instrumental vs. normal } \\
\text { vaginal birth }\end{array}$ & $1.40(1.08-1.83) p=0.012$ & $1.16(0.80-1.69) p=0.439$ \\
$\begin{array}{l}\text { Elective cesarean vs. normal } \\
\quad \text { vaginal birth }\end{array}$ & $2.44(1.96-3.03) p<0.0005$ & $2.75(2.08-3.63) p<0.0005$ \\
$\begin{array}{c}\text { Emergency cesarean vs. } \\
\text { normal vaginal birth }\end{array}$ & $3.15(2.40-4.13) p<0.0005$ & $2.47(1.77-3.46) p<0.0005$ \\
\end{tabular}

Note. Effects of variables are represented as odds ratio and associated $95 \%$ confidence intervals after adjusting for mother's parity, hospital location, and hospital type.

$n=65)$ and an elective CS $(4.1 \%, n=24)$ responding positively to this mental health item were much lower. A prevalence rate of $6.4 \%(n=165)$ was reported for women constantly reliving negative thoughts of birth and/or labor.

Logistic regression analysis revealed a significant association between reported psychological problems and mode of birth. Normal vaginal birth was used as the reference, and numbers of mental health problems were analyzed in reference selecting none, one, and/or two of the mental health items (Table 6). Women who had an emergency CS were more likely $(O R=3.10$, CI $=1.96-4.89, p<0.0005)$ to report constantly reliving negative aspects of labor and birth. They were also more likely $(O R=2.04, \mathrm{CI}=1.01-4.13, p=0.047)$ to confirm experiencing both psychological health items. Women who had an instrumental birth were also more likely $(O R=2.58, \mathrm{CI}=1.62-4.09, p<0.0005)$ to select constantly reliving negative aspects of labor and birth.

\section{DISCUSSION}

The results of this study suggest that a large number of Western Australian women do indeed experience one or more physical and/or psychological health problems in the postpartum period. This level of postpartum morbidity is consistent with previous research, which has reported the figure to be anywhere between $76 \%$ and $90 \%$ of postpartum women (Bastos \& McCourt, 2010; Glazener et al., 1995; MacArthur et al., 1991; Williams et al., 2007). Similarly, the occurrence of specific physical problems such as backache and urinary incontinence are strongly correlated with problems reported by women in the Australian Capital Territory and the state of Victoria (Brown \& Lumley, 1998; Thompson et al., 2002). The proportion of women experiencing fatigue, however, was almost half of that reported in Victorian and Australian Capital Territory studies. This may be because women were asked to report on "excessive"

TABLE 6 Association of Mode of Birth on Mental Health Problems Using Logistic Regression Analyses

\begin{tabular}{lcccc} 
& & \multicolumn{2}{c}{ MENTAL HEALTH PROBLEMS } \\
& $\begin{array}{c}\text { FEELING DOWN AND } \\
\text { UNHAPPY FOR MORE } \\
\text { THAN A FEW DAYS }\end{array}$ & $\begin{array}{c}\text { CONSTANTLY RELIVING } \\
\text { NEGATIVE ASPECTS OF } \\
\text { LABOR AND BIRTH }\end{array}$ & EITHER VS. NONE & $\begin{array}{c}\text { BOTH VS. NONE } \\
\text { OR EITHER }\end{array}$ \\
MODE OF BIRTH & $1.15(0.82-1.63)$ & $2.58(1.62-4.09)$ & $1.44(1.06-1.96)$ & $1.96(0.99-3.84)$ \\
Instrumental vs. & $p=0.422$ & $p<0.0005$ & $p=0.022$ & $p=0.052$ \\
normal vaginal birth & $1.32(0.98-1.77)$ & $1.11(0.67-1.83)$ & $1.32(1.00-1.73)$ & $0.86(0.41-1.80)$ \\
Elective caesarean vs. & $p=0.066$ & $p=0.689$ & $p=0.050$ & $p=0.687$ \\
normal vaginal birth & $1.25(0.87-1.78)$ & $3.10(1.96-4.89)$ & $1.72(1.25-2.35)$ & $2.04(1.01-4.13)$ \\
Emergency cesarean vs. & $p=0.224$ & $p<0.0005$ & $p=0.001$ & $p=0.047$
\end{tabular}

Note. Effects of variables are represented as odds ratio and associated $95 \%$ confidence intervals after adjusting for mother's parity, hospital location, and hospital type. 
fatigue as opposed to "fatigue" or "tiredness." In a review of international studies, Cheng and Li (2008) reported that between $15 \%$ and $76 \%$ of women experience fatigue or tiredness. Although differences in prevalence may be related to cultural backgrounds and/or number of children, it is nonetheless a condition that a large number of women experience and one that is also associated with maternal anxiety, stress, and depression. Nearly $16 \%$ of women reported experiencing prolonged unhappiness. Although this cannot be construed as postpartum depression, it suggests that many women are indeed experiencing some level of psychological distress ("Beyondblue," 2009; Thompson et al., 2002). In addition, the $6.4 \%$ of women who reported constantly reliving negative thoughts and/or images about labor and/ or birth - a symptom often associated with a distressing and/or traumatic birth (Beck, 2004) - is consistent with the 6\%-10\% identified in the United Kingdom's birthing population (Bastos \& McCourt, 2010).

The high level of postpartum morbidity reported in this study once again signals to maternity health care professionals that women's health needs after birth are significant. The messages inherent in these findings are especially important to midwives who are primarily responsible for providing care during a woman's early transition to motherhood.

\section{Physical Postnatal Morbidity and Mode of Birth}

The results of this study confirm that within the first 8-10 weeks after giving birth, women who have had a vaginal birth, in particular instrumental birth, are more likely to experience urinary incontinence (Arya, Jackson, Myers, \& Verma, 2001; Brown, Donath, MacArthur, McDonald, \& Krastev, 2010; Peschers, Sultan, \& Jundt, 2003; Thompson et al., 2002; Van Kessel, Reed, Newton, \& Lentz, 2001; Williams et al., 2007). Although the rates were lower in women birthing by CS, they were not absent, which is also consistent with previous work (Faundes, Guarisi, \& Pinto-Neto, 2001; Viktrup, Lose, Rolff, \& Barfoed, 1992). In this study report, loss of bowel control was steady across the birth mode groups and was not associated with spontaneous or instrumental vaginal birth. This result contradicts the work of MacArthur et al. (2003) who found that CS confers a protective factor in terms of anal sphincter control. High rates reported elsewhere may also be a result of some studies asking women to report on "bowel problems" as opposed to the more specific "loss of bowel control" (Thompson et al., 2002).
Although some purport that the risk of perineal morbidity, which includes urinary incontinence, is a justifiable reason for choosing a CS (Thornton \& Lubowski, 2006), this is a somewhat ill-informed position and does little to make a positive contribution to the debate and care of women. Firstly, although we are not able to comment on the longer term outcome for women in terms of urinary incontinence, the prospective cohort study by Thompson et al. (2002) indicated that by 6 months following birth, there was no difference in rates of urinary incontinence between the different modes of birth. Secondly, the causes of perineal morbidity are increasingly recognized as being multifactorial including some evidence that urinary incontinence is associated with intimate partner violence (Brown et al., 2010). In addition, research indicates urinary incontinence may have a genetic predisposition (Goldberg et al., 2005). Thirdly, the evidence is mounting that CS confers significant other short-term morbidity on woman (i.e., bleeding, infection, pain) and that this is related to subsequent infertility and substantially increased health care costs (Thompson et al., 2002; Williams et al., 2007). Finally, by the time women reach menopause, any differences in rates of urinary incontinence by mode of birth are "washed out by the equalizers of age, hypoestrogenism, declining urethral function, and genetic predisposition" (Goldberg et al., 2005, p. 2152).

Midwives and other maternity health care providers need to be cognizant that they share with childbearing women information about pelvic health regardless of birth mode. Women need to be respectfully engaged in evidence-informed discussion that facilitates decision making and the ability to access primary preventive measures as well as treatment strategies should they experience urinary incontinence. Midwives and obstetricians need to work together in partnership with women to keep birth normal. Limiting invasive obstetric procedures during the second stage of labor remains an important goal. As Bastos and McCourt (2010) point out, skilled care of the perineum during birth and in the postpartum period is vital to the physical comfort and emotional well-being of the childbearing woman.

In terms of the overall rate of physical morbidity, it was clear that women who had experienced a CS were more likely to suffer a multitude of problems in the early postpartum period. This is in line with the growing body of evidence that abdominal surgery for birth has a major impact on a woman's postpartum experience and quality of life (Lavender, Hofmeyer, Neilson, Kingdon, \& Gyte, 2006; Lydon-Rochelle, Holt, Martin, \& Easterling, 2000; McGovern et al., 2006; Thompson et al., 2002; Villar et al., 2007). Cesarean birth is also 
known to be associated with poorer neonatal outcomes (Villar et al., 2006). The finding that women who had a planned or elective CS suffered most is important. To date, a fairly consistent theme in the literature is that having an emergency CS holds a greater risk of physical morbidity for women. Further work into the physical morbidity relating to CS, and specifically categories of CS, is urgently needed. This should include both shortand long-term follow-up of women and their infants.

\section{Psychological Postpartum Morbidity and Mode of Birth}

The results of this work confirm that psychological morbidity in childbearing women is more likely to be present in women who experience invasive obstetric procedures such as instrumental birth and a CS (Bastos \& McCourt, 2010; Beck, 2004; Fisher, Astbury, \& Smith, 1997). The results that women who had an emergency or unplanned CS were more likely to report reliving negative thoughts or aspects related to the birth experience are not surprising and are consistent with the growing body of work in this area (see e.g., Barnes et al., 2007; Koo, Lynch, \& Cooper, 2003; Ryding, Wiren, Johansson, Ceder, \& Dahlstrom, 2004; Soderquist, Wijma, \& Wijma, 2002). Women giving birth by emergency CS were also more likely to select both the items that represented some level of emotional distress. Once again, women who have experienced an instrumental birth were also at increased risk for suffering postpartum psychological morbidity. Although our study did not seek information on women's future birth plans, the evidence indicates that those who suffer distress and/or trauma as a result of birth experience are more likely to reconstruct childbirth as an uncertain and a potential dangerous event (Fenwick, Gamble, \& Hauck, 2006). As a result, some women will choose never to have another baby (Porter, Bhattacharya, \& van Teijlingen, 2006), whereas others will choose a repeat elective CS, incorrectly believing that this mode of birth is safer (Amu, Rajendran, \& Bolaji, 1998; Bewley \& Cockburn, 2002; Fenwick et al., 2006). Consequently, all women who have experienced a CS need support for physical problems, whereas those with an emergency CS need both physical and psychological support in the postpartum period.

\section{Methodological Issues}

There are several methodological issues that need to be considered. The large sample size is the strength of this work providing some assurances that the results are generalizable. Although the age range of participating women compares with the state-based data except for women younger than 20 years old, it must be noted that the categories used in this study differed slightly from those used in the statewide perinatal database. Questions were also specific and asked women if they had actually experienced a particular health problem, whereas in some other studies, women have been asked which, if any, health problem they had experienced within a specified time period. As Brown and Lumley (1998) and later Thompson et al. (2002) have suggested, this may lead to an underestimation of the prevalence rates. One of the major challenges to interpretation of the results reported in this study, however, is that no data on participating women's preexisting health problems was collected. Thompson et al. (2002) similarly raised this issue stating that health problems could, thus, not be solely attributed to childbirth. The results reported in this article were also part of a larger study with a broad focus on women's perception of the care provided by midwives in the postpartum period. As a result, not all health problems reported in the literature were included. In addition, only two items to measure psychological morbidity were included. Again, these may not have adequately captured women's emotional well-being.

\section{CONCLUSION}

This study confirms that physical and psychological postpartum morbidity is indeed an area of concern and one that maternity health care providers, especially midwives, need to take seriously. Predominantly, the findings raise concerns around the impact of instrumental birth on perineal morbidity as well as contributing to the growing body of work that demonstrates poorer physical health outcomes for women who experience a CS regardless of category. The study results remain consistent with those of others. When possible, women need to be encouraged and supported to labor spontaneously and birth vaginally with minimal and appropriate levels of intervention. When an intervention such as an instrumental or surgical birth does occur, the potential for increased physical and psychological morbidity a woman may suffer needs to be acknowledged and additional support should be provided. Further work into the short- and long-term morbidity specifically relating to CS needs to continue. Organizers of maternity services need to seriously consider how postpartum 
services could be reorganized to improve the quality of care offered to women. Maternity service providers need to ensure that postpartum care is appropriately staffed by skilled midwives, well integrated and linked into the community services, and offers women some level of continuity of care when possible. To this end, research and clinical funding needs to be made available so that new postpartum services, some of which must target women with short- and long-term health problems, can be developed, implemented, and evaluated.

\section{REFERENCES}

Althabe, F., Sosa, C., Belizan, J. M., Gibbon, L., Jacquerioz, F., \& Bergel, E. (2006). Cesarean section rates ad maternal and neonatal mortality in low, medium and highincome countries: An ecological study. Birth, 33(4), 270-277.

Amu, O., Rajendran, S., \& Bolaji, I. I. (1998). Controversies in management: Should doctors perform an elective caesarean section on request? Maternal choice alone should not determine method of delivery. British Medical Journal, 317, 463-465.

Arya, L., Jackson, M. D., Myers, D. L., \& Verma, A. (2001). Risk of new onset urinary incontinence after forceps and vacuum delivery in primiparous women. American Journal of Obstetrics and Gynaecology, 185, 1318-1320.

Barnes, J., Altmann, L., Ram, B., Stein, A., Leach, P., Sylva, K. . . Families, Children and Child Care Team. (2007). Factors associated with negative emotional expression: A study of mothers of young infants. Journal of Reproductive and Infant Psychology, 25(2), 122-138.

Bastos, M. H., \& McCourt, C. (2010). Morbidity during the postnatal period: Impact on women and society. In S. Byrom, G. Edwards, \& D. Bick (Eds.), Essentials in midwifery practice: Postnatal care (pp. 113-137). London, United Kingdom: Blackwell.

Beck, C. (2004). Birth trauma: In the eye of the beholder. Nursing Research, 53(1), 28-35.

Begg, S., Vos, T., Barker, B., Stevenson, C., Stanley, L., \& Lopez, A. D. (2007). The burden of disease and injury in Australia 2003. PHE 82. Canberra, Australia: Australian Institute of Health and Welfare.

Bewley, S., \& Cockburn, J. (2002). I. The unethics of "request" caesarean section. British Journal of Obstetrics and Gynaecology, 109, 593-596.

Beyondblue: The national depression initiative. (2009). Retrieved from http://www.beyondblue.org.au/index. aspx?link_id $=94$
Bick, D. E . (2003). The importance of postnatal care. Journal of Midwifery, 11(10), 593.

Brown, S. J., Donath, S., MacArthur, C., McDonald, E. A., \& Krastev, A. H. (2010). Urinary incontinence in nulliparous women before and during pregnancy: Prevalence, incidence, and associated risk factors. International Urogynecology Journal and Pelvic Floor Dysfunction, 21(2), 193-202.

Brown, S., \& Lumley, J. (1998). Maternal health after childbirth: Results of an Australian population based survey. BJOG: British Journal of Obstetrics and Gynaecology, 105, 156-161.

Bruinsma, F., Brown, S., \& Darcy, M. A. (2003). Having a baby in Victoria 1989-2000: Women's views of public and private models of care. Australian and New Zealand Journal of Public Health, 27(1), 20-26.

Buist, A., \& Bilszta, J. (2005). The beyondblue national postnatal depression program prevention and early intervention 2001-2005. (Final Report. Vol. 1). Melbourne, Australia: Beyondblue.

Buist, A., Ellwood, D., Brooks, J., Milgrom, J., Hayes, B. A., Sved-Williams, A., . . . Bilszta, J. (2007). National program for depression associated with childbirth: The Australian experience. Best Practice \& Research. Clinical Obstetrics \& Gynaecology, 21(2), 193-206.

Cheng, C. Y., \& Li, Q. (2008). Integrative review of research on general health status and prevalence of common physical health conditions of women after childbirth. Women's Health Issues, 18(4), 267-280.

Commonwealth Department of Health and Aged Care, \& Australian Institute of Health and Welfare. (1999). National Health Priority Areas report: Mental health: A report focusing on depression. Canberra, Australia: Australian Institute of Health and Welfare.

Cooke, M., Sheehan, A., \& Schmied, V. (2003). A description of the relationship between breastfeeding experiences, breastfeeding satisfaction, and weaning in the first 3 months after birth. Journal of Human Lactation, 19(2), $145-56$.

Cooke, M., \& Stacey, T. (2003). Differences in the evaluation of postnatal midwifery support by multiparous and primiparous women in the first two weeks after birth. Australian Journal of Midwifery, 16(3), 18-24.

Creedy, D. K., Shochet, I. M., \& Horsfall, J. (2000). Childbirth and the development of acute trauma symptoms: Incidence and contributing factors. Birth, 27(2), 104111.

Faúndes, A., Guarisi, T., \& Pinto-Neto, A. M. (2001). The risk of urinary incontinence of parous women who delivered only by caesarean section. International Journal of Gynaecology and Obstetrics, 72, 41-46. 
Fenwick, J., Butt, J., Dhaliwal, S., Hauck, Y., \& Schmied, V. (2010). Western Australian women's perceptions of the style and quality of midwifery postnatal care in hospital and at home. Women and Birth, 23, 10-21.

Fenwick, J., Gamble, J., \& Hauck, Y. (2006). Reframing birth: A consequence of caesarean section for a selfselected group of western Australian women. Journal of Advanced Nursing, 56(2), 121-132.

Field, A. (2005). Discovering statistics using SPSS. 2nd ed. London, United Kingdom: Sage.

Fisher, J., Astbury, J., \& Smith, A. (1997). Adverse psychological impact of operative obstetric interventions: A prospective longitudinal study. Australian and New Zealand Journal of Psychiatry, 31, 728-738.

Gamble, J., Creedy, D., Moyle, W., Webster, J., McAllister, M., \& Dickson, P. (2005). Effectiveness of a counselling intervention following a traumatic childbirth: A randomized controlled trial. Birth, 32(1), 11-19.

Gee, V., Ernstzen, A., \& Le, M. (2008). Perinatal statistics in Western Australia, 2006. Twenty-fourth annual report of the Western Australian Midwives' Notification System. East Perth, Western Australia: Department of Health.

Glazener, C. M. A., Abdella, M., Stroud, P., Naji, S., Templeton, A., \& Russell, I. T. (1995). Postnatal maternal morbidity: Extent, causes, prevention, and treatment. BJOG: British Journal of Obstetrics and Gynaecology, 102, 282-287.

Goldberg, R. P., Abramov, M. D., Botros, S., Miller, J. J., Gandhi, S., Nickolov, A., . . Sand, P. K. (2005). Delivery mode is a major environmental determinant of stress urinary incontinence: Results of the Evanston-Northwestern Twin Sisters study. American Journal of Obstetrics and Gynecology, 193, 2149-2153.

Hauck, Y. L., Fenwick, J., Dhaliwal, S. S., \& Butt, J. (2011). A Western Australian survey of breastfeeding initiation, prevalence and early cessation patterns. Maternal and Child Health Journal, 15, 260-268.

Hauck, Y. L., Fenwick, J., Dhaliwal, S. S., Butt, J., \& Schmied, V. (2011). The association between women's perceptions of professional support and problems experienced on breastfeeding cessation: A Western Australian study. Journal of Human Lactation, 27(1), 49-57.

Hintz, J. (2008). Power analysis and sample size system (PASS 2008 software). Kaysville, Utah: NCSS, LLC.

Kendall, G. E., \& Li, J. (2005). Early childhood socialization and social gradients in adult health: A commentary on SinghManoux and Marmot's "role of socialization in explaining social inequalities in health" (60:9, 2005, 2129-2133). Social Science and Medicine, 61(11), 2272-2276.

Koo, V., Lynch, J., \& Cooper, S. (2003). Risk of postnatal depression after emergency delivery. Jounal of Obstetrics and Gynaecology Research, 29, 246-250.
Lavender, T., Hofmeyer, G. J., Neilson, J. P., Kingdon, C., \& Gyte, G. M. L. (2006). Caesarean section for non-medical reasons at term. Cochrane Database of Systematic Reviews, (3), CD004660.

Laws, P. J., Li, Z., \& Sullivan, E. A. (2010). Australia's mothers and babies 2008. Perinatal statistics series no. 24. Cat. no. PER 50. Canberra, Australia: Australian Institute of Health and Welfare.

Le, M., \& Tran, B. N. (2008) Perinatal statistics in Western Australia, 2008. Twenty-sixth annual report of the Western Australian Midwives' Notification System. Western Australia: Department of Health.

Leigh, B., \& Milgrom, J. (2008). Risk factors for antenatal depression, postnatal depression and parenting stress. BMC Psychiatry, 8, 24.

Lewis, G. (Ed.). (2004). Why mothers die. Confidential enquiry into maternal and child health. London, United Kingdom: Royal College of Obstetricians and Gynaecologists.

Lewis, G. (Ed). (2007). The confidential enquiry into maternal and child health (CEMACH). Saving mother's lives. The seventh report on confidential enquiries into maternal deaths in the United Kingdom. London, United Kingdom: The Stationery Office.

Lydon-Rochelle, M., Holt, V., Martin, D., \& Easterling, T. (2000). Association between method of delivery and maternal re-hospitalization. The Journal of American Medical Association, 283, 2411-2416.

MacArthur, C., Lewis, M., \& Knox, E. G. (1991). Health after childbirth. London, United Kingdom: Her Majesty's Stationery Office.

MacArthur, C., Winter, H. R., Bick, D. E., Lilford, R. J., Lancashire, R. J., \& Knowles, H. (2003). Redesigning postnatal care: A randomised controlled trial of protocol-based midwifery-led care focused on individual women's physical and psychological health needs. Health Technology Assessment, 7(37), 1-99.

McGovern, P., Dowd, B., Gjerdingen, D., Cross, C. R., Kenny, S., \& Ukestad, L. (2006). Postpartum health of employed mothers 5 weeks after childbirth. Annals of Family Medicine, 4, 159-167.

Miller, R., Pallant, J., \& Negri, L. (2006). Anxiety and stress in the postpartum: Is there more to postnatal distress than depression? BMC Psychiatry, 6(12), 1-11.

National Health Medical and Research Council. (1999). Postnatal depression: A systemic review of the published scientific literature to 1999. Canberra, Australia: Author.

O’Conner, T. G., Heron, J., Golding, J., Beveridge, M., \& Glover, V. (2002). Maternal antenatal anxiety and children's behavioural/emotional problems at 4 years: Report 
from The Avon Longitudinal Study of parents and children. British Journal of Pschiatry, 180, 502-8.

Perinatal Mental Health Consortium. (2008). National action plan for perinatal mental health 2008-2010 full report. Retrieved from www.gpsa.org.au/ . . . /mental health/perinatal_national_action_plan.pdf

Peschers, U. M., Sultan, H., \& Jundt, K. (2003). Urinary and anal incontinence after vacuum delivery. European Journal of Obstetrics and Gynaecology and Reproductive Biology, 110, 39-42.

Porter, M., Bhattacharya, S., \& van Teijlingen, E. (2006). Unfilled expectations: How circumstances impinge on women's reproductive choices. Social Science Medicine, 62(7), 1757-1767.

Ryding, E. L., Wiren, E. W., Johansson, G., Ceder, B., \& Dahlstrom, A. M. (2004). Group counselling for mothers after emergency cesarean section: A randomized controlled trial on intervention. Birth, 31(4), 247-253.

Sinclair, D., \& Murray, L. (1998). Effects of postnatal depression on children's adjustment to school. Teacher's reports. The British Journal of Psychiatry, 172(1), 58-63.

Soderquist, J., Wijma, K., \& Wijma, B. (2002). Traumatic stress after childbirth: The role of obstetric variables. Journal of Psychosomatics and Obstetric Gynecology, 23, 31-39.

Thompson, J. F., Roberts, C. L., \& Currie, M. (2002). Prevalence and persistence of health problems after childbirth: Associations with parity and method of birth. Birth, 29(2), 83-94.

Thornton, M. J., \& Lubowski, D. (2006). Obstetric-induced incontinence: A back hole of preventable morbidity. Australian and New Zealand Journal of Obstetrics and Gynaecology, 46, 468-473.

Van Kessel, K., Reed, S., Newton, K., \& Lentz, G. (2001). The second stage of labour and stress incontinence. American Journal of Obstetrics and Gynaecology, 184. 1571-1575.

Viktrup, L., Lose, G., Rolff, M., \& Barfoed, K. (1992). The symptoms of incontinence caused by pregnancy or delivery in primiparas. Obstetrics and Gynecology, 79, 945-949.
Villar, J., Carroli, G., Zavaleta, N., Donner, A., Wojdyla, D., Faundes, A., ... Acosta, A. (2007). Maternal and neonatal individual risks and benefits associated with caesarean delivery: Multicentre prospective study. British Medical Journal, 335(7628), 1025.

Villar, J., Valladares, E., Wojdyla, D., Zavaleta, N., Carroli, G., Velazco, A, . . A Acosta, A. (2006). Caesarean delivery rates and pregnancy outcomes: The 2005 WHO global survey on maternal and perinatal health in Latin America. The Lancet, 367(9525), 1819-1829.

Williams, A., Herron-Marx, S., \& Knibb, R. (2007). The prevalence of enduring postnatal mobidty and its relationship to type of birth and birth risk factors. Journal of Clinical Nursing, 16, 549-561.

World Health Organization. (1985). Appropriate technology for birth. Lancet, 2, 436-437.

Correspondence regarding this article should be directed to Jennifer Fenwick, PhD, RM, School of Nursing and Midwifery, Maternity and Family, Research Centre for Clinical and Community Practice Innovation (RCCCPI), Griffith Health, Griffith University, University Drive, Meadowbrook, Queensland 4131, Australia. E-mail: j.fenwick@griffith.edu.au

Jennifer Fenwick, PhD, RM, Professor of Midwifery, School of Nursing and Midwifery, Maternity and Family, Research Centre for Clinical and Community Practice Innovation (RCCCPI), Griffith Health, Griffith University, Queensland, Australia.

Yvonne Hauck, PhD, RM, Professor of Midwifery, Curtin Health Innovation Research Institute (CHIRI), Curtin University, Perth, Western Australia.

Virginia Schmeid, PhD, RM, Professor of Midwifery, School of Nursing and Midwifery, University of Western Sydney, Australia.

Satvinder Dhaliwal, PhD, Associate Professor, School of Public Health, Curtin University of Technology, Perth, Western Australia.

Janice Butt, MA (Ed), RM, Senior Midwifery Teaching Fellow, School of Nursing and Midwifery, Curtin University of Technology, and Coordinator of Midwifery Education, King Edward Memorial Hospital, Perth, Western Australia. 